\title{
La recepción de la Revolución Cubana en los Partidos Comunistas de América Latina
}

\author{
The reception of the Cuban Revolution in the Communist Parties \\ of Latin America
}

\begin{abstract}
Alexia Massholder ${ }^{*}$
Resumen: En 1959 el triunfo de la Revolución Cubana marcó sin duda un parte aguas para la historia de América Latina y también para el Movimiento Comunista Internacional. Las particularidades del proceso liderado por Fidel Castro inspirarían además nuevas reflexiones sobre las características de la Revolución en nuestro continente, y no sólo en él, y las formas de alcanzarlo. En este sentido, el debate acerca de la "vía" revolucionaria pasó a ocupar un lugar preponderante en los temarios de los partidos revolucionarios. El presente trabajo tiene como objetivo reconstruir la recepción de la Revolución liderada por Fidel Castro en los PC de Chile y Uruguay.
\end{abstract}

Palabras clave: Revolución Cubana-debates ideológicos, América Latina, vías

\begin{abstract}
In 1959 the triumph of the Cuban Revolution undoubtedly marked a watershed for the history of Latin America and also for the International Communist Movement. The particularities of the process led by Fidel Castro would also inspire new reflections on the characteristics of the Revolution in our continent, and not only in it, and the ways to achieve it. In this sense, the debate about the revolutionary "way" came to occupy a preponderant place in the agendas of the revolutionary parties. The objective of this paper is to reconstruct the reception of the Revolution led by Fidel Castro in the PCs of Chile and Uruguay.
\end{abstract}

Key words: Cuban Revolution, Latin America, ways, ideological debates

Recibido: 26 noviembre 2017

Aceptado: 15 febrero 2018

\footnotetext{
* Argentina Instituto de Estudios de América Latina y el Caribe (IEALC) de la Universidad de Buenos Aires. Investigadora de CONICET. Directora del Centro de Estudios y Formación Marxista Héctor P. Agosti (CEFMA). fmalexia@hotmail.com
} 


\section{Introducción}

El presente trabajo, parte de una investigación más amplia en curso, tiene como objetivo reconstruir la recepción por parte de los PC de Chile y Uruguay, tanto de sus direcciones como de la militancia en general, de un proceso histórico inesperado y heterodoxo para las vertientes dominantes del pensamiento marxista de aquellos años: la Revolución Cubana. Entrevistas a militantes de aquellos años nos permiten afirmar la existencia de amplios sectores de la militancia que saludaron con entusiasmo los acontecimientos en Cuba, más allá de la cautela que las direcciones pudieran mostrar a la hora de sacar conclusiones acerca de la pertinencia de la vía armada. Más allá de las declaraciones partidarias oficiales sobre el proceso cubano, y a pesar de las profundas divergencias con lo que se conoció luego como teoría del "foco", muchos militantes establecieron vínculos con la naciente Revolución. Debe decirse también que los PC desplegaron un importante movimiento de solidaridad con Cuba. En palabras de un militante comunista argentino:

Debo decir que, al margen de las elucubraciones internas sobre las enseñanzas de esa revolución, como el tema de la lucha armada, del fatalismo geográfico, etc., que contenían bastante desconfianza sobre la posibilidad de su éxito, desarrollamos una intensa campaña de solidaridad. Enviamos dinero, producto de colectas, brigadistas para la campaña de alfabetización, técnicos y profesionales de la salud y diversas disciplinas tecnológicas. ${ }^{1}$

La Revolución Cubana, en efecto, puso sobre la mesa del debate el tema de la lucha armada que, efectivamente, había tenido un lugar central en el triunfo de Fidel y sus hombres. En 1956 el XX Congreso del Partido Comunista de la Unión Soviética (PCUS) había dejado establecida la posición soviética de apoyo a la "vía pacífica" como principal estrategia revolucionaria. Esto incidió de manera diferente en los PC latinoamericanos al momento de realizar una lectura de la guerrilla comandada por Fidel Castro. Las lecturas no fueron homogéneas en todos los partidos ni tampoco al interior de sus estructuras. Hubo quienes rápidamente calificaron la experiencia cubana de "aventurerismo pequeño burgués" y quienes la vieron con mayor entusiasmo. Así, describir la recepción que la Revolución Cubana tuvo en los PCs de América Latina no es tarea sencilla. Como afirma Gerardo Leibner, es difícil "reconstruir hoy lo que fue el tremendo interés y, más aún, la amplia y profunda simpatía que provocó en Uruguay la Revolución cubana, al menos durante los primeros meses del triunfo". ${ }^{2}$ Esta posición sobre el caso uruguayo, puede ser extendida indudablemente a la militancia comunista de otros países.

Lo cierto es que, más allá de las expectativas, la "vía cubana" implicaba poner en cuestión las concepciones estratégicas imperantes en el comunismo latinoamericano, por lo menos en lo referente a la toma del poder y a las formas para lograrlo.

1Entrevista realizada por la autora a Jorge Bergstein, marzo del 2009. Bergstein fue secretario del PC argentino en la provincia de Córdoba en la década del '60.

2Leibner, Gerardo, Camaradas y compañeros. Una historia política y social de los comunistas del Uruguay, Montevideo: Trilce, 2011, p. 378 
En el presente trabajo plantea como hipótesis central que, si bien el impacto de la Revolución Cubana no produjo en los Partidos Comunistas latinoamericanos una revisión teórica y crítica de su posición sobre la "vía" revolucionaria, sí intentaron en algunos casos realizar lecturas alternativas que permitían pensar el proceso cubano como un fenómeno no necesariamente excepcional e irrepetible y del cual podían extraerse numerosas enseñanzas. Así, nos proponemos una aproximación a la recepción de aquella experiencia en los PC teniendo en cuenta principalmente las declaraciones oficiales. Para ello, partiremos de la reconstrucción de ciertos debates producidos al interior del PSP (Partido Comunista de Cuba) en vísperas del triunfo de la revolución.

\section{El triunfo de la Revolución Cubana y el Movimiento Comunista Internacional}

Para analizar las posiciones de los PC del continente deben tenerse presentes dos elementos fundamentales: en primer lugar, las características del Movimiento Comunista Internacional (MCI) en aquellos años; en segundo, la constitución subjetiva de los militantes comunistas de entonces. Respecto a lo primero, los partidos comunistas contaban preparación militar para sus cuadros más allá del proyecto insurreccional armado para la toma del poder que pudieran tener. En 1956, el XX Congreso del PCUS plantea la idea de mayores posibilidades de tránsito "pacífico" hacia el socialismo, dados los cambios en las correlaciones de fuerza mundiales y la creciente atracción que las ideas socialistas despertaban en obreros, campesinos y trabajadores de la intelectualidad. Menos de dos años después cincuenta y siete partidos aprueban una declaración, proyectada conjuntamente por el PCUS y el PC de China. La declaración alentaba los acuerdos y la colaboración política de partidos y organizaciones sociales para lograr la conquista del poder sin guerra civil, aunque sin descartar la posible necesidad de una vía no pacífica. Y la posibilidad real de una y otra vía de paso al socialismo, afirmaba la declaración, venía determinada por condiciones históricas concretas. ${ }^{3} \mathrm{El} \mathrm{XX}$ Congreso había confirmado la política de coexistencia pacífica con el bloque de países "no socialistas". Pero las implicancias de esta posición no eran las mismas para la URSS que para los PC que debían llevar adelante la lucha en sus países, hecho que trajo dificultades entre los propios comunistas.

Respecto a lo segundo, nos resulta muy útil el planteo de Karl Mannheim según el cual la formación de la conciencia tiene directa relación con las vivencias que se depositan como "primeras impresiones", como "vivencias de juventud", y cuáles sean las que vienen en un segundo o tercer estrato, ya que son las primeras impresiones las que tienden a quedar fijadas como una "imagen natural del mundo". ${ }^{4}$ El despertar político de aquellos que nacieron a principios del siglo $\mathrm{XX}$, se dio en un contexto internacional signado por al triunfo de la Revolución Rusa, el ascenso del movimiento comunista mundial, y un marcado humanitarismo antibélico en los años posteriores a la Primera Guerra Mundial. Este es el marco de las "primeras impresiones”, que permanecerán vivas y determinantes en

3Arismendi, Rodney, Lenin, Revolución y América Latina, México D.F: Grijalbo, 1976, p. 193.

4Mannheim, Karl, "El problema de las generaciones", en Revista Española de Investigaciones Sociológicas, No 62, Madrid. CIS www.reis.cis.es, p. 216. 
la recepción de acontecimientos históricos posteriores, y que permiten comprender, entre otras cosas, la admiración y el apoyo casi incondicional a la URSS como único exponente del socialismo realmente existente, y como portavoz de las consignas antibélicas y antifascistas de la primera mitad del siglo XX. La forma en la que el comunismo formó a sus militantes en estas concepciones, respondía al ejemplo de la Unión Soviética, y pueden ser hoy vistas de manera diferente. Pero en aquel momento constituía para muchos de los militantes comunistas un elemento más de aquello que había llevado a la Unión Soviética a ser lo que era. Repasemos además algunos datos que ilustrativos brindados por Fernando Claudín: luego de la Segunda Guerra Mundial había 14 millones de comunistas organizados fuera de la URSS. Antes, sólo cerca de 1 millón. En América Latina, se pasó de 90 mil en 1939 a 500.000 en 1947. El poderío mostrado por la URSS tras la Guerra reforzó su liderazgo frente al movimiento comunista internacional, y todos sus errores sería leídos como "exigencias inexorables" del proceso de su avance. ${ }^{5}$ Dicho esto, nos detendremos, además del caso cubano lógicamente, en los casos de los PC chileno, argentino y uruguayo.

Cuando se produce en Cuba el asalto al Cuartel Moncada en 1953, los comunistas estuvieron entre los primeros acusados por el gobierno de ser "autores intelectuales" de los hechos. Por ese motivo fueron arrestados inmediatamente Lázaro Peña y Joaquín Ordoqui. También se arrestó a los dirigentes comunistas José A. Cabrera, Antonio Pérez Mujica y Bernardo Hernández, "quienes fueron llevados al cuartel de esa ciudad y remitidos a Santiago de Cuba. En su tránsito por Camagüey, fueron ametrallados indiscriminadamente por un soldado y luego presentados en el juicio como heridos en las acciones del Moncada. ${ }^{6}$ Luego de estos hechos, el PSP pasó a la clandestinidad y comenzó a funcionar un nuevo Buró Político. Con todo, el PSP hizo pública su desacuerdo con el accionar en Oriente:

Todo el mundo sabe que el Partido Socialista Popular es el único que ha señalado el camino justo para resolver la crisis cubana: el camino de rechazar resueltamente las aventuras, el terrorismo y las 'expediciones', el camino de rechazar las 'componendas' y el aislacionismo [...] El camino escogido por Fidel Castro y sus compañeros es falso. Nosotros, que apreciamos su limpieza moral y que estamos convencidos de su honradez, tenemos que decir que el putch, que la acción armada desesperada y con categoría de aventura, no conducen a otra cosa que, al fracaso, al desperdicio de fuerzas, a la muerte de su objetivo. Tenemos que decir eso, y convencer a esos jóvenes, y a todos los jóvenes que piensan como ellos, que el camino es el de la lucha de masas y la acción de masas. ${ }^{7}$

5Véase Claudín, Fernando, La crisis del movimiento comunista, París: Ediciones Ruedo Ibérico, 1970, pp. 281-286.

6“¿Cómo detuvieron a los compañeros Cabrera, Antonio Pérez y otros?”, citado en Massón, Caridad, "Proyectos y accionar del Partido Socialista Popular entre 1952 y 1958", en el libro 1959: Una rebelión contra las oligarquías y los dogmas revolucionarios, Instituto Cubano de Investigación Cultural Juan Marinello y Ruth Casa Editorial, La Habana, Panamá, 2009.

7Carta Semanal, n. 16, 20 de octubre de 1953, citado en Massón, Caridad, "Proyectos y accionar del Partido Socialista Popular entre 1952 y 1958", en el libro 1959: Una rebelión contra las oligarquías y los dogmas revolucionarios, Instituto Cubano de Investigación Cultural Juan Marinello y Ruth Casa Editorial, La Habana, Panamá, 2009. 
Esto no impidió que cuando Fidel saliera de la cárcel, el PSP desplegara una importante campaña denunciando las intenciones del gobierno de atentar contra la vida del joven revolucionario. Con todo, las posiciones al interior del PSP tuvieron sus matices, como bien lo recuerda el propio Juan Marinello:

[e]xistían diversas opiniones. Finalmente, logramos imponernos lo que teníamos confianza en Fidel y en su victoria. Y apoyamos la lucha guerrillera. [...] En primer lugar, Blas [Roca], que con esa gran visión que tenía vio en Fidel al gran Líder. También Carlos Rafael [Rodríguez] -en 1958 subió a la Sierra enviado por el partido-, Flavio Bravo, Lionel Soto, Osvaldo Sánchez y otros compañeros que apoyaron la lucha guerrillera. ${ }^{8}$

La investigadora cubana Caridad Massón, ha reproducido en uno de sus trabajos sobre la historia del PSP una entrevista a Edith García Buchaca, quien en 1956 viajó a la URSS junto a Blas Roca para participar del XX Congreso del PCUS y a un ciclo de conferencia brindadas por el PC de china. Allí puede leerse:

Por aquella época -recuerda Edith- imperaba el criterio de que las revoluciones armadas victoriosas solo podían darse en países que reunieran determinadas características, entre ellas un amplio territorio y posibilidades de autoabastecimiento en momentos críticos, atribuyéndose gran importancia a las zonas montañosas para la guerra de guerrillas. De acuerdo con ello, se excluía a Cuba de toda posibilidad de una victoria por vía insurreccional [...] Cuando comenzaron las conferencias sobre las guerras de guerrillas y la lucha armada, donde se explicaba de forma minuciosa la táctica seguida en diferentes territorios y sus experiencias durante actividades militares prolongadas, yo le pregunté a Blas si debía tomar en detalle aquellas ideas. Su respuesta fue que las tomara, pues a pesar de todas las teorías, nadie sabía lo que podría suceder y si nos serían útiles en cualquier momento'. ${ }^{9}$

De hecho, en mayo de 1956 el PSP resolvió hacer un reajuste táctico dado que la dictadura en complicidad con el imperialismo había minado las posibilidades de la lucha parlamentaria y pacífica:

No somos adoradores de la violencia por sí misma [...] -planteaba un manifiesto del 26 de septiembre. Por eso formulamos y enarbolamos a su tiempo -nosotros antes

8Báez, Luis, "Memoria inédita. Conversaciones con Juan Marinello", La Habana, Editorial SI-MAR S.A, 1995, p. 165. Massón comenta que, en julio de 1958, el PSP envió como su representante a Carlos Rafael Rodríguez a la Comandancia de la Plata en medio de la ofensiva del ejército de la tiranía y de combates tan significativos como la batalla de El Jigüe. Una vez terminada la ofensiva, el dirigente comunista bajó a reunirse con el Comité Nacional del PSP y se tomaron nuevas decisiones a partir de las circunstancias existentes. En tres semanas, Rodríguez regresó definitivamente a las montañas en calidad de representante de su Partido, a fin de acudir al llamado hecho por Fidel a todos los sectores oposicionistas a congregarse en la Sierra para iniciar desde allí la ofensiva final. Esa exhortación tuvo poca acogida entre las restantes organizaciones opositoras.

9Massón, op. cit. 
que nadie- la consigna de las elecciones generales democráticas e inmediatas, con garantías para todos los partidos y zonas de opinión, que franqueaba la posibilidad de dar salida por vía electoral, sin graves convulsiones, a ciertas de las graves cuestiones que afectan el momento nacional. Pero cuando el gobierno despótico que padecemos - con el apoyo de sus amos imperialistas yanquis- bloquea la vía electoral y pretende mantenerse en el poder por la fuerza, no hay más remedio que apelar a la acción extraparlamentaria, es decir, a la lucha directa de las masas, elevándola a la altura que fuera menester -incluso la insurrección popular- para liberar a nuestra Patria de la opresión y abrir paso a las soluciones que necesita el pueblo.

Este cambio de línea permitirá que en noviembre de ese mismo año el PSP empezara coordinar ciertas acciones con el Movimiento 26 de Julio (M-26). Las discusiones al interior del Partido respecto a cuál era la posición correcta llevó a avances y retrocesos entre ambos grupos, hasta que en noviembre de 1957 el PSP acuerda con el M26 en la creación de un frente unitario que garantizara una huelga general revolucionaria. Si bien hubo acciones en conjunto, las reservas entre ambos sectores prevalecieron. Con todo, para 1958 el PSP no sólo estaba involucrado en acciones armadas junto al M-26 sino que fue el responsable de un destacamento guerrillero en Las Villas. En marzo de 1958 el PSP publicaba un artículo en el que explicaba el porqué de su apoyo a los combatientes en Sierra Maestra, luego de que todas las vías de acción pacífica se habían cerrado. El Partido, escribe Massón, envió un Memorándum urgente a Fidel Castro en el cual señalaba que a pesar de existir entre ambas organizaciones diferencias en cuanto a programa e ideología, coincidían en la necesidad de tumbar a la tiranía, por lo cual asumía como decisiva la coordinación entre ambas organizaciones, por ello el Partido orientó en cada centro de trabajo la creación de comités que contribuyeran la agitación, organización y movilización del paro; que establecieran contactos con las secciones obreras de los distintos partidos para combinar acciones y acordar las fechas de ejecución. Es importante señalar que la posición tanto de los miembros de la dirección del PSP como de sus militantes no fue homogénea ni lineal, y que convivieron dentro de la organización sectores que se involucraron en la guerrilla y sectores que insistían en que la lucha armada traería una represión aun mayor por parte de los EEUU.

Luego del simulacro electoral de noviembre de 1958, el PSP llamó a sostener la lucha armada y aumentar con acciones reivindicativas en todo el territorio nacional de modo coordinado con el M-26-7, con quien ya se estaba trabajando en casi todas las zonas del país. De hecho, la experiencia organizativa del PSP contribuyó decisivamente al éxito de algunas operaciones. De las experiencias recogidas en la lucha común, el PSP extrajo en mayo de 1959 las siguientes conclusiones:

1.- Que, en América Latina, aún en pequeños países, era posible la lucha de guerrillas para derrocar un régimen pro imperialista; que la lucha armada podía ser la forma fundamental, mientras que la huelga, el movimiento de masas, acciones obreras en las ciudades jugaran un papel auxiliar.

2.- Que la unidad de las fuerzas oposicionistas era fundamental para el triunfo, pues el movimiento popular no pudo convertirse en factor principal en 1933 por el divisionismo 
prevaleciente, el espíritu economicista, el control de los mujalistas sobre los sindicatos, la resistencia de ciertos sectores a integrar un frente con los comunistas.

3.- Que en las acciones guerrilleras los trabajadores agrícolas y campesinos pobres pueden constituirse en fuerzas esenciales.

4.- Que, en este tipo de países neocoloniales, ciertas capas de la pequeña burguesía, pese a sus contradicciones de clase, no deben desestimarse, pues sus elementos más radicales se pueden fusionarse con el proletariado e impulsar la revolución agraria.

5.- Que la revolución cubana resultó un duro golpe al fatalismo geográfico y al imperialismo y fortaleció con su ejemplo el movimiento de liberación nacional a nivel mundial. ${ }^{10}$

Se hicieron las autocríticas del caso, se dejaron de lado las diferencias secundarias en favor de la unión de los revolucionarios.

La importancia decisiva que tuvo el movimiento urbano para las acciones no sólo del Moncada sino para el triunfo del M-26 en su accionar rural, ha sido señalada por Nils Castro en Las izquierdas latinoamericanas en tiempos de crear. Allí el autor resume dicha importancia en dos ejes: en primer lugar, porque cuando Fidel se exilia la rebeldía urbana prosiguió, con mayor coherencia y efectividad a escala nacional, y cuando llega el Granma el movimiento urbano tenía articulación nacional y los estaba esperando. En segundo lugar, por el traslado varios jóvenes armados desde la ciudad a la Sierra Maestra. El "llano" realizó diferentes aportes a "la sierra", para que ésta pudiera desplegar más efectivamente su accionar. Para el autor,

El entusiasmo por la Revolución Cubana llevó a algunos sectores a tergiversar la experiencia real allanando el camino a toda una serie de errores conceptuales, como ocurrió con el foquismo. El dato efectivo es que la experiencia cubana nunca probó que un pequeño foco guerrillero pudiera por sí sólo atraer a un pueblo a la guerra revolucionaria; en Cuba la resistencia social empezó con anterioridad a la guerrilla, y el Llano sostuvo a la Sierra durante un largo período, hasta que esta pudo sostenerse por sí misma. Mucho menos demostró que fuera posible alzar a las masas populares $-\mathrm{y}$ ni siquiera al proletariado- convocándolas en nombre de una propuesta armada explícitamente socialista y hasta marxista-leninista. Antes bien, en Cuba la gente se rebeló porque repudiaba los latrocinios y abusos de la tiranía y porque un joven dispuesto a jugarse la vida junto con sus compañeros [...] ganó su credibilidad ofreciéndoles un proyecto cívico de raigambre martiana, fraternal, ético y solidario, y bien insertado en la cultura política que prevalecía en su sociedad y su tiempo: lo más revolucionario que en aquel momento se podía asumir [...] Que este arraigado sentimiento pudiera encontrar sustentación teórica en el socialismo y el antiimperialismo es algo que la mayoría de los cubanos sólo conoció después. ${ }^{11}$

Simultáneamente, vemos, se producía una fisura en las posiciones del MCI: se abría con hechos concretos el debate sobre la vía revolucionaria.

\footnotetext{
10Pleno del Comité Central del PSP, citado en Massón, op. cit.
}

${ }^{11}$ Castro, op. cit., 70-77. 


\section{El caso chileno}

Para el análisis de cualquier aspecto de los partidos comunistas en esta época debemos insistir en el marco de la Guerra Fría que, en América Latina, aunque no sólo, determinó la ilegalización de los comunistas y el nombramiento de dictadores como Somoza, Trujillo, Strossner y Batista por parte de los Estados Unidos. Este contexto, vastos sectores de la izquierda colocaron como uno de los objetivos principales de su accionar la recuperación de la democracia, a pesar de sus limitaciones burguesas.

Desde principios de los años '50 el PC chileno había tenido en su interior fuertes debates sobre la vía revolucionaria protagonizados nada menos que por el Secretario General del Partido, Galo González, y el Secretario de Organización, Luis Reinoso. El primero sostenía los planteos del llamado "Programa de Emergencia", es decir, la necesidad de conformar un gobierno democrático de liberación nacional a través de la un frente de amplia coalición. Su objetivo principal no era combatir al capitalismo sino terminar con la dominación imperialista y feudal, para luego encaminarse hacia el socialismo. El segundo, era partidario del empleo del brazo armado contra la dictadura desarrollando la guerrilla urbana. Pero la comisión política apoyó la posición de González y la discusión quedó cerrada. A partir de entonces, el Frente de Liberación Nacional se desarrolló con el Partido Socialista en lo que se llamó Frente del Pueblo y que se presentara en las elecciones presidenciales de 1952 con Salvador Allende como candidato.

La estrategia de las alianzas recibió un impulso especial luego del XX Congreso del PCUS, aunque debe tenerse en cuenta que la elaboración de la línea del PC chileno tuvo siempre una especial contemplación por la propia realidad nacional. En palabas de Alonso Daire:

Habría una fuerte dependencia del PC de Chile en relación a las políticas del MCI [Movimiento Comunista Internacional, pero sobre todo la URSS]. Una "ágil obsecuencia" para seguir las líneas de la política exterior de la URSS y del PCUS. Pero esto no hay que entenderlo sólo como un seguidismo y fuerte solidaridad con "el país del socialismo" en el escenario internacional, sino que esto traspasa, aunque no directamente, el ambiente político nacional [...] Es decir, hay una autonomía creadora del PC de Chile en el diseño de estrategias políticas que obedecen a una asimilación realista del estilo y vida política chilena, considerada históricamente, y que por otro lado, existe una fuerte dependencia en cuanto a acudir a los llamados de la política exterior de la URSS y del PCUS.

En este sentido, es importante subrayar que la estrategia de la vía pacífica sostenida en el XX Congreso del PCUS, no hacía sino fortalecer la línea que el propio Partido chileno había enunciado en su IX Conferencia Nacional de 1952.

Cuando la Revolución Cubana triunfa en 1959, el MCI se encontraba convulsionado por las revelaciones del XX Congreso del PCUS, los sucesos de Hungría y el incipiente conflicto chino-soviético, este último centrado, justamente, en las discusiones sobre la vía al socialismo. El PC chino había manifestado su oposición a una de las tesis de apoyo a la vía pacífica sostenidas por el congreso soviético de 1956, por considerarla una negación de los principios de la propia Revolución de Octubre en Rusia, y que reducía la estrategia 
política a la vía parlamentaria. Para los chinos, la lucha por la revolución debía sostenerse en "dos piernas", esto es, la lucha armada y la vía pacífica. A estas dos posiciones encontradas se suma en 1959 la experiencia concreta de la Revolución Cubana. En 1961 El Che publica en la revista Verde Olivo un artículo sobre las particularidades del caso cubano, que contribuyeron a la victoria de la Revolución. Una de las conclusiones centrales del artículo era que "[a]unque no esté excluida la posibilidad de que el cambio en cualquier país se inicie por vía electoral, las condiciones prevalecientes en ellos hacen muy remota esa posibilidad". ${ }^{12}$ El Che agregaba que en caso de un movimiento popular ocupara el gobierno e intentara avanzar en grandes transformaciones, el ejército intentaría derribarlo mediante un golpe de estado iniciando inevitablemente un conflicto armado.

Pero sin duda el texto que más desarrolla estas ideas es Guerra de guerrillas, en donde el Che niega la necesidad de esperar a que las condiciones estén dadas, sino que pueden ser creadas por un foco guerrillero, esbozando una crítica a los "pseudorevolucionarios" que "se sientan a esperar a que, en una forma mecánica, se den todas las condiciones objetivas y subjetivas necesarias, sin preocuparse de acelerarlas". ${ }^{13} \mathrm{El}$ Che proponía además la centralidad del campesinado frente a la primacía casi absoluta que la teoría leninista otorgaba al proletariado urbano. Esto resultaba claramente apartado de la propuesta del PC chileno. Pero dicha propuesta, no se remitía a las directivas del XX Congreso del PCUS, como bien lo demostrara Luis Corvalán en la revista Principios números 77 y 86 de enero y octubre de 1961. En un principio, además, el PC chileno no prestó mayor atención a lo que estaba ocurriendo en Cuba. Esto se debió, según Daire, a que no sólo el PSP no estaba comandando aquella lucha, sino a que la guerra de guerrillas no era una vía que el partido chileno considerara como válida. Más aún, miembros de la dirección partidaria llegaron a calificar a los guerrilleros cubanos como "aventureros pequeño burgueses". ${ }^{14}$ Hubo, sin embargo, una valoración del proceso cubano en un artículo titulado "La vía pacífica y la alternativa de la vía violenta", aparecida en el número 86 de Principios. Corvalán señala entonces que la Revolución Cubana abría una nueva perspectiva al incorporar la guerrilla como vía revolucionaria. Aunque el autor sostiene que aquella vía no era trasladable a otras realidades latinoamericanas, representaba una demostración de que la revolución era posible "en cualquiera de nuestros países". Y en ocasión del XIII Congreso del PC Chileno, Corvalán afirmaba que "[c]onforme a sus propias características nacionales, con métodos y formas que correspondan a cada realidad particular, todos los pueblos latinoamericanos seguirán el ejemplo cubano". ${ }^{15}$

En la conferencia de los 81 Partidos Comunistas de 1960, sin embargo, el delegado del PC chileno José González reafirmó la desconfianza hacia la "herejía cubana" y la

12“Cuba ¿Excepción histórica o vanguardia en la lucha anticolonialista? Verde Olivo, 9 de abril de 1961, p. 27.

13Guevara, Ernesto, La guerra de guerrillas, disponible en www.librodot.com

14Ver Joaquín Fermandois, "Chile y la cuestión cubana", en Historia número 17, Universidad Católica 1982, p. 134.

15 Corvalán, Luis, Tres períodos en nuestra línea revolucionaria, Berlín: Dietz Verlag, 1982. p. 12. Afirmación similar hará el dirigente chileno durante la celebración del OLAS en agosto de 1967. Véase Yopo, Boris, "Las relaciones internacionales del Partico Comunista", en Varas, Augusto, El Partido Comunista en Chile, Santiago: CESOC-FLACSO, 1988, p. 385 
posición de los chinos. ${ }^{16} \mathrm{Y}$ a pesar de la creciente atención que despertaba la Revolución Cubana y la incidencia que ésta tuvo en sectores de la izquierda chilena, entre ellos el ala izquierda del Partido Socialista, el PC chileno siguió manteniendo su posición respecto a la vía pacífica, que mantendría hasta la victoria de la Unidad Popular que llevó a Salvador Allende a la presidencia del país. La vía pacífica tenía en Chile una larga tradición desde 1935 y hasta iniciativas como el Frente de Liberación Nacional (FLN) de 1949 a 1956, que en 1952 lleva a Allende como candidato, y luego el Frente de Acción Popular (FRAP), línea que quedó consolidada en el X congreso del PC chileno en abril de 1956 y que sería el germen de la Unidad Popular.

Como otros partidos comunistas, el PC chileno optó por concentrar fuerzas en las vías pacíficas de luchas, relacionadas a las reivindicaciones democráticas, la lucha por la paz, por la soberanía nacional, por las libertades públicas que estaban para Corvalán "en el centro de la actividad de la clase obrera en todos los países capitalistas, aún en aquellos donde el socialismo es un objetivo más próximo. Podría decirse incluso que el camino del socialismo pasa a través de a lucha por las reivindicaciones de este carácter por el hecho de que es la forma concreta en que el proletariado aísla a sus enemigos principales y acumula fuerzas". ${ }^{17}$ Los procesos sociales, agregaba, "no se dan en la vida según esquemas preestablecidos y lo importante no son los esquemas sino que se den esos procesos. En este terreno, la Revolución Cubana rompió precisamente muchos esquemas y demostró que pueden llegar al socialismo fuerzas que en los primeros pasos de la revolución sustentan en algún grado una ideología burguesa". ${ }^{18}$ Precisamente por eso, "son los revolucionarios de cada país los que determinan, en todos sus aspectos, el rumbo y las tareas concretas que conduzcan a su propia revolución. Ellos conocen más que nadie la realidad en que actúan y están en mejores condiciones para trazar sus objetivos y los métodos para alcanzarlos [...] La Revolución Cubana ha sido una demostración palpable de cómo la vida rompe los esquemas, de que no se puede generalizar ninguna experiencia en lo que tiene de singular". ${ }^{19}$ En vísperas de la Organización Latinoamericana de Solidaridad (OLAS), Corvalán publicó un artículo en la Revista Internacional en el que reconocía que en algunos países de América Latina podía crearse con éxito un foco guerrillero al estilo cubano, siempre que se tuvieran "condiciones generales favorables, no decimos enteramente favorables y plenamente maduras, pero sí en proceso de maduración, con perspectivas de madurar. Descubrir el lugar y momento preciso para iniciar una acción de tipo guerrillero y otra forma de lucha armada que pueda ser el punto de partida para la conquista del poder, no es, por cierto, cosa fácil. Lenin alertaba contra el peligro de aventuras que suelen conducir al sacrificio inútil de valiosas vidas de revolucionarios y al retroceso del movimiento. Sin embargo, el leninismo se caracteriza por la audacia creadora [...] Por ello, no se puede rechazar de plano ni aceptar a fardo cerrado ninguna forma de lucha". ${ }^{20}$

16 Daire, Alonso, "La política del Partido Comunista desde la post-guerra a la Unidad Popular", en Varas, Augusto, El Partido Comunista en Chile, Santiago: CESOC-FLACSO, 1988, p. 188.

17 Corvalán, op. cit., 14.

18 Corvalán, op. cit., 18.

19 Corvalán, op. cit., 34.

20 Citado en Corvalán, op. cit.,35. 
Sin dudas, la OLAS fue un momento fundamental en los debates sobre la vía revolucionaria. Luego de la Primera Conferencia Tricontinental de Solidaridad Revolucionaria, la OLAS apostó claramente a la lucha armada. No es un dato menor que su presidente fuera Salvador Allende, uno de los más férreos luchadores antiimperialistas, pero que defendió la vía pacífica al socialismo para el caso particular de Chile.

Boris Yopo ha afirmado que "la concepción de la UP [Unidad Popular] fue una realización de la práctica y el pensamiento comunista. La creación de la UP, en cuanto al carácter de la alianza, es la realización de las aspiraciones del PC". ${ }^{21}$ Lo cierto es que luego de haberse presentado como candidato presidencial en 1952, 1958 y 1964, Salvador Allende es elegido presidente en septiembre de 1970. Así leía el intelectual comunista Volodia Teitelboim aquella victoria:

[E]l movimiento popular chileno ha enriquecido la práctica social dando un nuevo aporte creador a la historia de la lucha por la emancipación de los trabajadores, al demostrar conforme a las leyes siempre vívidas y frescas de un marxismo creador, que el pueblo es capaz de hacer muchos caminos nuevos, y que por todos los caminos válidos puede llegar a la Roma nueva de la sociedad nueva, del socialismo contemporáneo. ${ }^{22}$

El fracaso de las experiencias guerrilleras en la segunda mitad de los años '60, y el progresivo estrechamiento de las relaciones entre Cuba y la URSS luego del fracaso de la "zafra de los diez millones", sumada al triunfo electoral de la Unidad Popular, acercaron aún más las relaciones entre los PC chileno y cubano.

\section{La perspectiva uruguaya}

Pocos trabajos han problematizado tanto el tema de las vías como Lenin, la Revolución y América Latina, de Rodney Arismendi. Secretario General del PC uruguayo desde 1952, Arismendi dedicó numerosos artículos no sólo a la táctica y la estrategia revolucionaria sino al particular caso cubano. Como bien lo indica su título, el libro contiene diferentes trabajos que apuntan a recuperar el pensamiento de Lenin, principalmente Dos tácticas... El Estado y la Revolución y Guerra de guerrillas, trabajo del cual comienza citando: "los revolucionarios que no saben combinar las formas ilegales con todas las formas legales son malísimos revolucionarios". Y para Arismendi, la misión histórica del Partido es justamente reunir "la unidad programática, la unidad táctica y la unidad de organización" que garantice el trabajo en ambas formas de lucha.

El escritor y dirigente uruguayo afirma que "la concepción marxista - leninista de las vías de la revolución es, en gran parte, el reverso, mejor dicho, la derivación natural de su teoría del estado en general y de la dictadura del proletariado en particular (...) He aquí la subrayada importancia que Marx, y luego Lenin, asignan a la experiencia de la Comuna de París, demostrativa de que la revolución socialista deberá destruir la 'máquina

21 Yopo, Boris, "Las relaciones internacionales del Partico Comunista", en Varas, Augusto, El Partido Comunista en Chile, Santiago: CESOC-FLACSO, 1988.

22 Teitelboim, Volodia, “El pueblo y su gobierno”, en Principios, № 137, enero-febrero de 1971. 
burocrático-militar del estado' y no solamente apoderarse de ella (...) Al generalizar esta experiencia, Marx y Lenin le otorgan un carácter histórico - universal, es decir, teórico y metodológico. Por lo tanto, el problema hoy llamado específicamente de las vías de la revolución no puede ser resuelto por un marxista - leninista como si fuera una simple cuestión táctica más o menos circunstancia." ${ }^{23}$ Lo central para el autor es comprender que lo que varía es la correlación entre los distintos medios de lucha, tanto legales como ilegales. Así lo había enseñado Lenin en sus Dos tácticas, cuando, incluso partiendo de la convicción de la necesidad de insurrección armada para el derrocamiento del zarismo, evaluó la inexistencia de condiciones concretas para el asalto al poder por esa vía. Se iniciaba entonces un período de "preparación", en la que no hay acción política directa de las masas y en la que "la palabra también es un acto", es decir, la agitación y la propaganda tienen un profundo carácter revolucionario. En este sentido, la insurrección armada era la conclusión indispensable más allá de que momentáneamente no se hiciera un llamamiento directo. Se trataba en cambio de un período de preparación, de acumulación de fuerzas. Y esta es la diferencia central entre vía y medios de lucha.

Partiendo de estos razonamientos, Arismendi hace un muy interesante análisis de las Declaraciones de 1957 y 1960 del movimiento comunista internacional. Momentos claves en las polémicas que comenzaban a desatarse a raíz del a Revolución Cubana. Las conclusiones erróneas que se derivaron de aquellos escritos, incluso para descalificar el proceso cubano, se debían a la incomprensión de que las tareas y posibilidades de la época señalaban un ensanchamiento de la probabilidad del tránsito pacífico en algunos países, pero de ninguna forma establecían la anulación de la vía armada. En muchos casos, "el texto de estos documentos internacionales se usa a veces en sustitución del análisis de la situación concreta de una sociedad o una región dadas; con ello no se determina la vía probable de la revolución, apenas si se esgrime una fórmula a la que, por ese sólo hecho, se la ha quitado la sangre y la vida, olvidando que en realidad, lo general sólo puede manifestarse en lo singular y particular." 24 Porque el concepto de ley histórica, como recuerda Arismendi,

no equivale en el marxismo a un determinismo ciego y mecanicista (...) Son leyes tendenciales, señalan la dirección principal del desarrollo en una sociedad y en una época determinada (...) como lo recuerda Engels, la historia de por sí no hace nada, la historia la hacen los hombres; ocurre en un cuadro objetivo determinado, pero es obra al fin de esos hombres, que introducen, en la faena, la gama compleja de sus errores y aciertos potenciales. ${ }^{25}$

Recuperar el marxismo como guía, como método, frente al dogmatismo, pero también frente al revisionismo, implicaba "tomar en cuenta el contenido objetivo del proceso histórico en un momento dado y en una situación dada, a fin de comprender, en primer lugar, cuál es la clase cuyo movimiento es la principal fuerza motriz del progreso

23Arismendi, op. cit., 102-103.

24 Arismendi, op. cit., 114.

25 Arismendi, op. cit., 160. Se refiere al trabajo de Engels "L. Feuerbach y el fin de la filosofía clásica alemana". 
posible en esa situación dada". ${ }^{26}$ Vías, medios y formas de lucha, sólo pueden abordarse, en definitiva, por la "estimación concreta de la correlación de fuerzas en pugna [que] permitirá decir la última palabra acerca del desarrollo también concreto de un proceso revolucionario." 27

También Marx sentenciaba que "La insurrección sería una locura allí donde la agitación pacífica puede conducir hacia el objetivo por una vía más rápida y más segura". ${ }^{28}$ Pero esto no significaba descartar su tesis fundamental de la expropiación de los expropiadores, dado que más allá de las formas concretas en las que se desarrollara esta expropiación, se trataba igualmente de un acto de violencia revolucionaria. Y esta última, varía en su intensidad de acuerdo a la capacidad de resistencia de las clases dominantes frente a los intentos de expropiación, es decir, de la propia dinámica de la lucha de clases.

Uno de los aportes fundamentales de Arismendi para el MCI, y sobre todo en América Latina, en su lectura de la Revolución Cubana es el considerarla no como un "hecho aislado" sino como parte de un proceso de revolución continental. "Luego de Cuba y en la época de tránsito del capitalismo al socialismo, el curso general de la revolución latinoamericana es ahora irreversible. Ni el imperialismo yanqui, ni la clase obrera y los pueblos de América Latina pueden volver a vivir ya como antes". ${ }^{29} \mathrm{Y}$ en otro de sus trabajos agregaba: "Prescindir de las particularidades de la revolución cubana, más aun de su rotunda singularidad, fue y es, una simpleza política. Pero considerarla - desde el punto de vista latinoamericano - como un accidente histórico o una exclusividad más o menos caprichosa, parece - si el diagnóstico es benigno - por lo menos un caso de miopía." ${ }^{30}$ En su libro Problemas de una Revolución Continental Arismendi resalta la importancia histórico-universal por tres motivos: por ser una clara muestra del contenido de su época, por encarnar radicalmente las tareas de la revolución latinoamericana, y ha reinstalado los debates sobre la lucha armada. Para el autor, es justamente mérito de los revolucionarios cubanos el planteo de la revolución en términos continentales, no con la idea de "exportar la revolución, sino en el sentido en el que lo había hecho, por ejemplo, Simón Bolívar. Por esa misma razón, "la solidaridad con Cuba es (...) un planteamiento de largo alcance una tarea estratégica de la revolución latinoamericana". 31

La experiencia cubana planteaba para el autor dos líneas de trabajo. Por un lado, el análisis de las cuestiones específicamente cubanas, y por otro lado, su proyección continental, no sólo por la irradiación potencial de una experiencia socialista en América Latina, sino también en lo referente a las estrategias revolucionarias de nuestros pueblos. "Seguimos creyendo, con Lenin, - escribe Arismendi - que no se trata de imitar a nadie. Pero sí, de valorar lo esencial de cada experiencia, y la experiencia cubana es la única que

26 Lenin, citado en Arismendi, op. cit., 135.

27 Arismendi, op. cit.,158.

28 Citado en Arismendi, op. cit., 137.

29 Arismendi, Rodney, Problemas de una Revolución Continental, Montevideo: Ediciones Pueblos Unidos, 1962, p. 16.

30 Arismendi, op. cit.,273.

31 Arismendi, Rodney, Problemas de una Revolución Continental, Montevideo: Ediciones Pueblos Unidos, 1962, p. 26. El destacado pertenece al original. 
corresponde a una revolución triunfante de este continente; no puede mirarse pues, con ligereza.

Con todo, los PC de nuestro continente recibieron una fuerte conmoción, ya que la experiencia cubana

replanteó el problema de las vías en la revolución en América Latina. Le dio actualidad, quitándole el polvo de la especulación teórica y exponiéndolo a la intemperie, al sol, al viento y a la lluvia, de una realidad palpitante (...) 1959 es, además, una fecha significativa por otros motivos. Han pasado tres años del vigésimo Congreso del PCUS que verificara la posibilidad de que algunos países, en condiciones peculiarmente favorables, pudieran arribar al socialismo sin insurrección armada o guerra civil (...) La victoria cubana - fruto de un planteamiento consciente, estratégico, de la vía armada y aún más, del uso inteligente dentro de ésta de una forma o método principal, la guerrilla - parece un contrapeso irónico puesto por la historia a esas exageraciones. ${ }^{32}$

Arismendi critica por igual a quienes convirtieron en dogma aquellos postulados del XX Congreso del PCUS, y las declaraciones de 1957 y 1960 antes mencionadas, y a quienes luego de la experiencia cubana "piensan que todo consistirá en repetir ceñidamente aspectos de la lucha guerrillera", en un similar caso de dogmatismo, que esquematizan y "resecan" la experiencia cubana "que, justamente, entre otras cosas, rompe violentamente la estrechez de los esquemas (...) Deberá situarse, cuando sea menester, críticamente en otros países, es decir, adecuarse a sus correlaciones de fuerzas, pero es una experiencia insoslayable (...) no negaremos que en circunstancias muy propicias en alguno de nuestros países latinoamericanos, el pueblo pueda acceder al poder por un camino relativamente pacífico; empero, la línea principal de la liberación será la lucha armada. Lo recuerda nuestra historia, lo muestra nuestra realidad sociopolítica, lo enseña a palmetazos sangrientos, el imperialismo de los EEUU'. 33

\section{Conclusiones}

La Revolución Cubana marca el inicio de una de las décadas más convulsionadas del siglo XX, la década del '60, cuyos cimbronazos afectaron también a los Partidos Comunistas. El fenómeno produjo una gran conmoción en el Movimiento Comunista Internacional. Los intentos por trazar en dicho movimiento una táctica común válida para todos los países generaron tensiones a la hora de realizar una lectura sobre la vía por la que el grupo liderado por Fidel Castro había logrado conquistar el poder en Cuba. Como vimos, los propios comunistas cubanos tuvieron divergencias a la hora de trazar una aproximación a lo que estaba ocurriendo en la isla. Los casos chileno y uruguayo que hemos ilustrado en este escrito nos permiten afirmar que la recepción no fue homogénea, y tendieron a oscilar entre una posición más coincidente con los cubanos, como la representada por Arismendi, y el caso del PC chileno que partiendo de una valoración de lo ocurrido en Cuba se esforzó por desarrollar la vía pacífica a partir de su experiencia de la UP. Los debates entre cubanos

32 Arismendi, op. cit., 308.

33 Arismendi, op. cit., 309-310. 
y chilenos darán cuenta luego de la complejidad de dicho proceso. Pero esto será objeto de un próximo trabajo.

\section{Bibliografía}

Libros o monografías, revistas y artículos en revistas, prensa diaria o periódica

-Arismendi, Rodney, Lenin, Revolución y América Latina, México D.F: Grijalbo, 1976.

-Arismendy, Rodney, Problemas de una Revolución Continental, Montevideo: Ediciones Pueblos Unidos, 1962.

-Báez, Luis, "Memoria inédita. Conversaciones con Juan Marinello", La Habana, Editorial SI-MAR S.A, 1995.

-Castro, Nils, Las izquierdas latinoamericanas en tiempos de crear, La Habana: Editorial de Ciencias Sociales, 2012.

-Claudín, Fernando, La crisis del movimiento comunista, París: Ediciones Ruedo Ibérico, 1970.

-Corvalán, Luis, Tres períodos en nuestra línea revolucionaria, Berlín: Dietz Verlag, 1982.

-Daire, Alonso, "La política del Partido Comunista desde la post-guerra a la Unidad Popular", en Varas, Augusto, El Partido Comunista en Chile, Santiago: CESOC-FLACSO, 1988.

-Leibner, Gerardo, Camaradas y compañeros. Una historia política y social de los comunistas del Uruguay, Montevideo: Trilce, 2011.

-Massón, Caridad, "Proyectos y accionar del Partido Socialista Popular entre 1952 y 1958", en 1959: Una rebelión contra las oligarquías y los dogmas revolucionarios, Instituto Cubano de Investigación Cultural Juan Marinello y Ruth Casa Editorial, La Habana, Panamá, 2009. -Teitelboim, Volodia, "El pueblo y su gobierno", en Principios, № 137, enero-febrero de 1971. -Yopo, Boris, "Las relaciones internacionales del Partico Comunista", en Varas, Augusto, El Partido Comunista en Chile, Santiago: CESOC-FLACSO, 1988.

Fuentes electrónicas o digitalizadas -Guevara, Ernesto, La guerra de guerrillas, disponible en www.librodot.com

-Mannheim, Karl, "El problema de las generaciones", en Revista Española de Investigaciones Sociológicas, $\mathrm{N}^{\circ}$ 62, Madrid. CIS www.reis.cis.es

Entrevistas

-Entrevista realizada por la autora a Jorge Bergstein, marzo del 2009 